\title{
Children's Violently Themed Play and Adult Imaginaries of Childhood: A Bakhtinian Analysis Rachel Rosen
}

Children's imaginative play about violent themes has long been contentious within educational policy, parenting literature, and the academe in the Anglophone world, with conflicting views as to its immediate and long term consequences. Scholarship in this field points, on the one hand, to concerns that such ludic activity is limited by media scripts (Levin and Carlsson-Paige 2006) and related to non-play aggression (Dunn and Hughes 2001). In contrast, another group of studies have found no clear correlations (e.g. Parsons and Howe 2006) and indicate there are numerous methodological limitations to research which infers a causal link between violently-themed play and aggression (Goldstein 1995). Others have argued that play with violent themes can be cathartic (Singer 1994), as well as support the growth of imagination and social relationships (Holland 2003), ethical identities (Edmiston 2008), physical skills (Pellegrini 2006), and literacy (Dyson 1997).

Amongst educators, violently-themed play is similarly the subject of intense debate, often preoccupied with whether it should be allowed or prohibited in early childhood settings (Holland 2003). Perspectives in this debate are, at least in part, influenced by the social positions of observers. Connor's (1989) research suggests that distinctions made between play fighting and actual aggression depends in part on gender, childhood experiences with violently-themed play, and profession; with early childhood educators more likely to attribute actual aggression to play scenarios.

Despite growing awareness of the impact adult views about childhood have on research and practice more generally (Dahlberg et al. 2007), only limited attention has been given to the way debates about children's violently-themed play are informed by adult imaginaries of childhood. Imaginaries are those commonly-held systems of values and meanings about who is a child; the competencies and characteristics association with those considered to be children; and ideas about the 'proper' activities and knowledge associated with childhood. The notion of imaginary is important in that it calls attention to the historical constitution of meanings at the cognitive level but also at the emotional and symbolic, such as the stories and images through which such ideas are carried. In considering why violently-themed play is often discouraged in preschool settings, Sutton-Smith (1997) is a notable exception in his attention to imaginaries of childhood. He argues that this is often the result of adult views that their role is to bring rationality to childhood and because of concerns that children are often "in charge" in such play, a reversal of taken-for-granted power relations. 
In seeking to extend this small body of scholarship, this article will offer an in-depth exploration of the imaginaries of childhood which occupied educator narratives of, and responses to, violently-themed play in an early childhood setting in London, England. Such play was permitted according to setting policy; in practice, educators' perspectives and embodied communication was far more complex and contradictory. Such inconsistencies, it will be argued, are not an indication of individual confusion nor did differences between educators merely reflect individual preferences. Rather, this paper will work with conceptualisations offered by the Bakhtinian circle $^{1}$ to suggest that the educators' ambivalent responses to violently-themed play can best be understood as "double-voiced" (M. Bakhtin 1986), containing direct and indirect quotations of contradictory imaginaries of childhood and adult-relations. Despite the presence of such heterogeneity, the article will examine the ways in which particular practices and narratives combined to occupy an authoritative status in the setting, in ways which reified violently-themed play and obfuscated important pedagogical questions. The argument offered has broad implications not only because debates about violently-themed play operate beyond the study setting but because it raises possibilities for thinking otherwise about such ludic activity as well as childhood.

\section{The Bakhtinian frame}

This paper seeks to build on a small body of work which has similarly noted the potentiality of Bakhtinian ideas for early years scholarship, including research about themes of death (Löfdahl 2006) and violence (Edmiston 2008). In so doing, the paper will focus specifically on two concepts in the vast Bakhtinian oeuvre: dialogism and hetero/monoglossia.

Dialogism posits that an utterance, which is extended here to include embodied and nonverbal forms of communication animating everyday practices (White 2009; Albon and Rosen 2014), does not hold meaning in its abstracted form. Nor does meaning reside in an individual psyche which is then manifested in a speech act. Instead, the Bakhtinian circle is insistent that meaning occurs in the space between the speaker/author and listener/writer. Meaning, Vološinov (1986) suggests metaphorically, is "like an electric spark that occurs only when two different terminals are hooked together" (p.103). Thus, from a dialogic perspective, meaning is always contextual.

Whilst highly situated, this utterance is "only a moment in the continuous process of verbal communication" (Vološinov 1986, p.95). The dynamic relationship between previous and future utterances is at the heart of Bakhtinian dialogism where the utterance is always "half

\footnotetext{
1 The 'Bakhtinian circle' refers to the group of Soviet thinkers, including Valentin Vološinov, who engaged in a scholarly dialogic community around Mikhail Bakhtin.
} 
someone else's" (M. M. Bakhtin 1981). On one side of the utterance is the past. This includes the speaker to whom a response as well as the way that words and the meanings "joined" to them are borrowed from the immediate conversation or more distant interactions; cultural imaginaries; the socio-political order; and material conditions. Yet, an utterance is never entirely imitative as the speaker puts her own intention on it, albeit borne out of her specific history rather than inner authenticity (Burkitt 1998), and uses it in an always unique context. Notwithstanding this singularity, utterances are constrained by "speech genres" which are those relatively ossified relations of production and power that impose the conditions of possibility for what can be said and how (M. Bakhtin 1986). On the other side of an utterance is the reply. In dialogism, this does not just refer to the actual response of the listener. Instead, an utterance is always populated with the anticipated rejoinders of others. What is said, as well as how, always already includes the context in which it is inserted. As different voices "interanimate" each other, the possibility of utterances being "double-voiced", or containing conflicting quotations, is ever present.

It is this interplay between contradictory voices and meanings (heteroglossia), and centripetal forces which unify meaning (monoglossia), which is central to the dialogic nature of language and indeed the self and the social world. Bakhtin (1981) affirms the necessity of monoglossia for some degree of mutual understanding. If the meaning of any utterance was completely mobile, a language would be unable to offer any possibility of shared comprehension. Communication would be impossible. But, in order to create this unity, monoglossia acts as a disciplinary and normalising force, seeking to constrain destabilising heteroglossia. Bakhtin is insistent, however, that in this dynamic interplay, heteroglossic or centrifugal voices do not disappear although they may be submerged. In this way, the apparent unity of meaning in monoglossia is always only posited and never guaranteed. Bakhtin champions the creative potential of heteroglossia in part as a hopeful response to dominant groups' imposition of their own monoglossic meanings as eternal truth claims.

\section{An ethnographic study of violently-themed play}

The data discussed in this paper comes from an 18 month ethnographic study investigating socio-dramatic and fantastical play involving imaginary death and pretend physical violence that had the intent of killing, maiming, or stopping another character (a broad definition following Dunn and Hughes 2001). The research involved being at Westside Nursery ${ }^{2}$ one day a week as a semi-participant observer, joining as a co-player when invited. The data reported in this article were generated in a variety of ways. Field notes were taken either

${ }^{2}$ All names of people and places are pseudonyms. 
during or just immediately after observing a session and these "scribbles" - with all the omissions and imprecisions this term implies (Jones et al. 2010) - were turned into longer fieldnotes at the end of each day. Data was also generated through formal and informal interviews with children and adults. Six educators were interviewed following the first phase of research and ten were interviewed at the end. In addition, three group interviews were held with educators. Interviews were recorded through audio or note-taking and then transcribed. This paper is based on observational data as well as interviews, both formal and informal ethnographic interviews, with educators.

Educators' practices and utterances about violently-themed play from all data sources were grouped thematically. The data in each theme was subjected to a "Bakhtinian interpretive analysis" (Tobin and Kurban 2009) which involved tracing the voices and genres which populated the responses and considering the contexts, both immediate and more distal, which were anticipated. Illustrative data for each theme has been included in this paper. For simplicity, all longer utterances in the article come from individual interviews where educators were asked: What are your perspectives on children's imaginative play about themes of death and violence? Less attention is paid to these interpersonal interactions in the paper, a tension given the Bakhtinian insistence on holding both the immediate and distal in play. Given the limitations space, this focus does, however, allow for a fuller examination of the more distal audience.

\section{Context of the study}

Given the importance placed on context in dialogism, a brief background to Westside Nursery is crucial. The Nursery is one of only 423 local authority-run settings in England (Deparment for Education 2012), operating on a non-profit basis and run by a communitybased governing body with staff employed by the local authority. The setting reflects the significant increase in non-familial early years provision in England over the past 15 years. This includes the introduction of a statutory early years curriculum; incorporation into the national inspectorate regime: Office for Standards in Education, Children's Services and Skills (OfSTED); and the development of Children's Centres in low-income communities. This rapid growth, however, has been accompanied by the marketization of the sector creating a climate of competition for "customers" even amongst those settings which operate on a non-profit basis (Penn 2011, p.157).

During this study, the newly-elected government maintained a focus on the early years sector whilst instituting a series of adjustments to funding and operation. Some changes were only proposed or piloted, such as a "payment by results" model; the uncertainties they 
brought with them, however, created a sense of unease throughout the early years sector (e.g. see Moss 2011) including Westside Nursery. Tracking children's attendance, raising children's assessment profiles, and OfSTED reports - all potential criteria for determining payment by results (Valle et al. 2011) and part of the monitoring culture of neo-liberal educational reforms more broadly (Ball 2003) - were mentioned frequently at staff meetings and given extensive attention in practice.

There were 40 part-time and between 30-40 full-time children enrolled in the setting at any one time during the study. They ranged from 2-4 years old and came from diverse religious, ethnic, and cultural communities. All children in the setting received a national entitlement for part-time education, and those in full-day care received further government funding.

Seventeen women formed the primary educational team. Nearly all had been at the setting for over a year and many had worked there for over five years. This may partially account for the similarities in accounts offered about children's violently-themed play which are discussed in the following section.

Day-to-day, children were encouraged to engage in a variety of activities both indoors and outdoors for the first part of the session and were brought together for educator-led activities in the later part of the session. Children's violently-themed play generally took place in the more open part of the session and often in the outdoor space away from adults. Although, the mobility of the play meant the play was often at least peripherally observed by the educators. Marauding zombies, fire-breathing dragons and monsters that ate the boiled heads of humans were frequent characters. Play themes also involved warfare between soldiers, less narrativised gun battles, and traffic accidents causing death and destruction.

\section{Double-voiced responses to children's violently-themed play}

Children's violently-themed play was largely permitted in the policy at Westside Nursery, paralleling shifts that have taken place in the English early years sector. Until the 2000s most early childhood settings in London explicitly forbid such play (Holland 2003). However, a recent piece of non-statutory guidance in England encourages educators to lift bans and actively facilitate play based on children's interests, including ludic activity involving weapons and superheroes, in order to support learning and development (Department of Children, Schools and Families 2007). In this policy context, it was not surprising that in the same period Westside Nursery had shifted from an outright prohibition of violently-themed play to officially permit it.

Despite sanctioning violently-themed play, educators' narratives and practices were far more complex and contradictory. The sections that follow will trace some of these double-voices to 
the contradictory imaginaries of childhood and social relations which they cite. The point here is neither to disparage individual educators for the contradictions between their official policy and practice nor to put forward a deterministic argument about the impact of broader social forces. Instead, the article seeks to trace the shifting and locally enacted dynamic between heteroglossia and monoglossia.

\section{Contradictions: Children's interests and concerns with inertia and progress}

The policy permitting violently-themed play was explained by educators through reference to supporting children's development by attending to their preoccupations:

Muznah: At first, the policy was that they shouldn't do weapon play. Then, we let them at least do it safely with modelling from adults. We decided to talk about it and teach about it, because they are so interested.

In numerous interviews, educators expressed their commitment to "building on children's interests" for effective curriculum planning. This notion has become virtually monoglossic in the English early childhood sector (Brooker 2011), and it is enshrined in the national curriculum incorporating recommendations from an influential study which provided supplied justifications for the cognitive development provided by adult extensions of child-initiated activities (Sylva et al. 2003). Building on children's interests also cites a dominant rhetoric where play more broadly is viewed as the natural occupation of children which can accordingly be mobilised pedagogically (Sutton-Smith 1997). Recognition that children not only have interests and opinions that matter, but also have the right to be listened to, is reiterated at a global scale in the UN Convention of the Rights of the Child, as well as General Comment No. 7: Implementing child rights in early childhood which affirmed that all aspects of the UNCRC applied to all children, even the very young.

Nowhere was the narrative of children's interests and development more apparent than in the association of boys and violently-themed play:

Hayat: Boys mainly go through a stage where they have to go through physical fighting games.

Indeed, Browne (2004) suggests that sensationalised fears of boy's underachievement in schools has to a large degree motivated a more recent turn to violently-themed play as a venue for supporting boys' development. She notes that this is based on an argument that the neglect of boys' purportedly natural interests and characteristics are viewed as contributing to their alienation and lower levels of achievement in schooling. Changes to the policy at Westside Nursery were populated by this shifting 
'consensus' in the broader early years field. Suffice it here to say that this not only runs the risk of marginalising boys who do not 'develop' through such play or girls who do but it reifies the socio-political, and indeed economic, mediations of desire and interest.

For the purposes of this article, the key point to make is that there is a heteroglossia at play in national policies and educator's citations of them. The national curriculum tasked educators to simultaneously follow children's interests and to support children's progress towards standardised early learning goals. This placed pressures on educators when children did not appear to be meeting their goals of supporting children to "learn through play" or when violently-themed play did not map clearly on to the "highly prescriptive" early learning goals and "detailed network of norms and criteria" in the curriculum (Moss 2012, p.135).

A commonly used phrase in expressing these tensions is that children were "getting stuck" in violently-themed play:

Pansy: They almost get really stuck in this play and to move them on is really difficult. Cause that's all they've got. And they don't know how to move out of it. For some they say, 'OK, that was that' and they move on, 'We're finished'. I know for Paul the other day, he found it really hard and he was totally stuck...

"Getting stuck" was associated with violently-themed play, rather than other types of ludic activity, partially because educators felt that aspects of violently-themed play at Westside Nursery could not be "built on" in order to meet teleological early learning goals. Violently-themed play was often disordered, un-verbalised, and potentially contravening of the established social order in its preoccupation with topics considered outside the purview of childhood innocence (see below).

Framing the issue in relation to stasis and lack of motion generated a particular type of solution: at Westside Nursery, educators spoke about the need to "move children on". Implying as it does a sense of inertia, the metaphor of "getting stuck" necessitated an externally-applied force to "move children on". In this case, the outside force was generally assumed to be an adult. As a result, many of the staff primarily observed violently-themed play, with their occasional interactions designed to "move the play on" - injecting it with particular narratives which often redirected it or using the play themes within adult-led lessons in language and literacy - or stop it.

In many ways, these concerns about children's perceived immobility and inertia, and the concomitant difficulty of effecting normative momentum, anticipate a regulatory and policy context where the educational field is constructed as one of human capital development. If 
educators could not be viewed as "adding value" (Bradbury, 2011) to the child their professional identity and endeavours might be viewed as failures not only symbolically but materially in the form of negative OfSTED evaluations, lowered demand for their programme, and employment repercussions in the marketised early years sector. The corollary here is that the children who were labelled as "getting stuck", were often held accountable and even stigmatised - within a neoliberal discourse of individual selfmaximization and responsibilisation - for what were deemed to be inappropriate interests or making incorrect choices in activities. Whilst following children's interests, as linked to children's participation rights, has its roots in the more emancipatory recognition of children as competent social actors, in the interplay with meeting early learning goals, this practice had the consequence of reproducing adult-child relations in which adult surveillance, monitoring, and intervention to "move it on" assumed centrality.

\section{Contradictions: Vulnerability and safety, risk, and containment}

Tashelle: We decided that if gun play was done as an activity it wouldn't get as out of hand as if it was done in secret areas because adults could guide in terms of safety, encourage 'nicer play' and negotiation. Before it was allowed, children with stronger personalities would bully or be scary for others in gun play.

As Tashelle's response to the question "What are your perspectives on children's imaginative play about themes of death and violence?" indicates also at stake in educators' responses to children's violently-themed play was concern for children's safety. In no way seeking to downplay these genuine anxieties about children's well-being, the suggestion here is that Tashelle's comments can also be understood dialogically, reverberating with a series of double-voiced quotations.

On the one hand, Tashelle's comments call up a series of long-standing adult imaginaries of childhood as a time of innocent vulnerability in need of protection from the harsh realities of the world. The biological vulnerability of infants has often been extended to all children to the point that Christensen (2000, p.39) argues that vulnerability has become a "master identity" of childhood. This conflation is compounded by the intensification of a risk society where risk discourses are "pervasive" in early childhood settings (Bialostok and Kamberelis 2010, p.301). On one hand, managed risk-taking is valorised. For instance, educators made efforts to create physically challenging outdoor activities such as high climbing structures and obstacle courses. These physical spaces were often used in children's violently-themed play, offering affordances in keeping with the perilous aspects of play narratives: a climbing frame was turned into a jail where a monster trapped, cooked, and ate its prisoners and a climbing rope became a noose in a series of ludic executions by hanging. 
On the other hand, by highlighting multiple, often imperceptible threats, risk discourses amplify concerns about safety particularly when elided with imaginaries of childhood vulnerability. Indeed, safety discourses have become virtually monoglossic across the Anglophone early childhood sector. Wyver et al. (2010, p.263) argue that educators in these countries operate in a context of "surplus safety", often attempting to prevent any type of danger for fear of even the most benign injury. In navigating the heteroglossic tensions pulling in contradictory directions of promoting risk-taking and ensuring safety, the educators at Westside Nursery generally planned and set-up activities aimed at promoting physical risk-taking. Their direct interactions and interventions seemed to be based upon concerns about children's vulnerability:

Dhurata: It's a health and safety thing. We have to protect them. They aren't contained. They are oblivious to others.

Such a focus, which often trumped the promotion of managed risk-taking at Westside Nursery, was unsurprising given the attribution of vulnerability to young children and the related need for adult supervision and protection enshrined in the accountability-driven early years sector in England.

Often at work alongside notions of childhood vulnerability are those of innate innocence which has become the "paradigmatic, modern, western conception of childhood" since the Romantic period (Smith 2011, p.26). Imaginaries of childhood as a "golden age" of goodness are often productive of pedagogical environments that focus on "protection, continuity, and security" (Dahlberg et al. 2007, p.45). Mobilisation of themes in play, such as death and violence, which call up the harsh realities of everyday life can come to seem decidedly out of place and, by corollary, even constituted as inappropriate forms of knowledge for children who are constructed as innocent. It is perhaps this tension which Kelly was grappling with when she noted her discomfort in following children's interests and engaging in ludic violence:

Kelly: I don't think that's a conscious decision. But that would feel uncomfortable. I suppose because everything you're doing is to protect and look after children.

However, imaginaries of childhood are subject to heteroglossic forces: concerns about the child as vulnerable are challenged by views of the child as dangerous to others. Indeed, Tashelle's comments also call up an imaginary of the child, or at least those with "stronger personalities", as dangerous and uncontrolled without the support, stability, and judicial boundary-setting which can, within this narrative, only be offered by adults. Imaginaries of the feral child were carried in other educator utterances, such as "the children move in a pack", "it can be frenzied", "the play is uncontained", and "it is gang culture already". These 
comments have deep historical roots in puritanical views which construed childhood as rooted in original sin (Valentine 1996) and Hobbsian views of childhood as a state of "being as yet unschooled and untamed"(Spry 2013, p.6).

Concerns over children's play which was constituted as dangerous or animal-like particularly if left to their own devices in the hidden spaces of the nursery - were also articulated in relation to the educators' other statutory responsibilities. At play here is the responsibility to ensure "school readiness", where educators are effectively seen to serve as both a redemptive force tasked with compensating for supposed lacks in (working class) children's families (Dahlberg and Moss 2005) and a 'civilising' force between an assumed natural infant/child and a student prepared for the demands of more formal, compulsory schooling and even as a member of a "'stable, well-prepared' workforce for the future" (Dahlberg et al. 2007, p.45). In these double-voiced narratives and practices such play continued to be viewed uncomfortably, largely characterised as a site for containment efforts or else at risk of disastrous outcomes.

\section{Silent voices of heteroglossia}

In contrast to the previously discussed narratives and practices, which were widely reiterated during the course of the study, there was another set of responses which are referred to here as the silent voices of heteroglossia. This includes utterances made in individual interviews which did not carry through to more public conversations and practices and were largely unrepeated during the course of the study. These silent voices included one educator's concerns about the tension between violently-themed play and her Christian views on peace or, in another case, the view that such play might normalise forms of aggressive masculinity. These also included brief references to the difficulty of engaging, as adults, in such play with children given the way that it unsettled previously discussed concerns with the role of educators as one of containment:

Interviewer: How do you feel about joining in this play?

Dhurata: They want to be in control. They want to shoot at you. Want you to lay down and be dead. Maybe it is a Freudian thing: 'Shoot her, she made me clean up.'

Dhurata's double-voiced uptake of an imagined child perspective is significant here because of the discomfort it indicates with the play given its potential to unsettle the more monoglossic shape of adult-child relations in the setting, echoing imaginaries of childhood noted by Sutton-Smith (1997) in the introduction.

The silent voices of heteroglossia also include the few times when educators were observed to join in with children's violently-themed play. Notably, when asked to reflect on how other 
educators viewed their approach to violently-themed play, those educators who got involved in the play or at least explained their approach in this way, identified this as undesired by other educators in the setting. Eva, for instance, spent some describing the way she would get involved with such play before the following conversation took place:

Interviewer: What do you think others think of your views of play about death and violence? Educators and children.

Eva: Probably as far too condoning of it. [laughs]

Interviewer: Children or educators?

Eva: Educators. Children I think they know you for who you are... Actually it keeps them busy, entertained and learning. Then why not? But not everybody would agree with me. I think it's health and safety... I am disapproved of sometimes...

Without tracing the imaginaries populating each of these utterances, suffice it here to note the plurality of double-voiced quotations operating in the setting, albeit that those discussed in this section were less publicly articulated and widely taken up, a point which will be returned to below.

\section{Violently-themed play as "matter out of place"}

The discussion thus far has traced some of the sources for educator's double-voiced narratives and practices in relation to violently-themed play. It has highlighted the heteroglossic forces at play including contradictory imaginaries of children as dangerous, vulnerable, "stuck", malleable and rights holders; conflicting perspectives about violentlythemed play as troubling, a natural preoccupation particularly of boys, and either good or bad for the future; as well as paradoxical imperatives for educators including following children's interests, ensuring pre-set developmental outcomes, protecting children, and encouraging risk-taking. These certainly leant unpredictability to educators' double-voiced responses. From a Bakhtinian (1981) perspective, whilst centripetal and centrifugal forces always exist in a dynamic tension, monoglossia always struggles to subsume heteroglossia and can come to dominate at any given point. In this context, centripetal forces rendered violently-themed play permissible in policy, given the emphasis on following children's interests and the reification of violently-themed play as boys' natural proclivity, but taboo in practice.

Taboos, argues Mary Douglas (1966), serve the purpose of controlling ambiguity and systems of ordering. Given the heteroglossic nature of the social world, there are always anomalies which strain at monoglossic forces which seek to impose particular ways of ordering. Taboos act to make anomalies appear as "matter out of place", for instance when 
children who are seen as innocent and vulnerable engage with what is constituted as adult knowledge about death and violence. When policy and pre-existing adult-child relations constitute early childhood settings as spaces where educators protect and "add value" to young children, violently-themed play which cannot be recuperated for pedagogical purposes becomes "matter out of place" pushing at the boundaries of the aspirational developmental and safe spaces of childhood.

Potential violations of a taboo are closely monitored and confronted in an effort to produce conformity with existing social imaginaries (Douglas 1966). Taboos may function by labelling anomalies as dangerous, much in the way that violently-themed play was linked to the need for adult interventions for health and safety. They are also imposed through the reiteration of a singular interpretation of events, such as the persistent repetition of the metaphor "getting stuck". Taboos function through confrontation, much as violently-themed play was often stopped or "moved on" at Westside Nursery. In order to maintain the monoglossic façade that such play was permitted in the setting, however, such interventions largely took the form of imperatives about health and safety or developmentalism, rather than engaging directly with the content of the play itself.

The argument here is that the status of violently-themed play as permitted in policy but taboo in practice was a strong centripetal pull during the period of this study in part because this was over-populated with recurrent voices operating, both spatially and temporally, well beyond the walls of the setting. Therefore, although this centripetal unity was locally produced, it is likely analogous to other early childhood settings given the movement of narratives and practices across scales. For instance, policy, media, academic research and public imaginaries locally, nationally and globally are saturated with concerns with health and safety, developmentalism, and the vulnerability of childhood. The monoglossic pull at Westside Nursery also drew force from the anticipated audience of utterances and practices in response to violently-themed play. In the more proximal, violating this monoglossia led to concerns that they may be disapproved of or found wanting by other educators. The more distal audience also exerted influence. Potential challenges were dis-incentivised through the prospect of negative repercussions for the setting and concomitant job security in the competitive early childhood market-place in England. In the climate of austerity measures and impending payment-by-results, access to resources served as potential incentives for conforming to particular ways of categorising and indeed constituting practices. Particular practices were reinforced by intensive monitoring and the resultant valuations of practice this brought with it. 
Despite the seeming dominance of this centripetal pull during the period of study, the silent voices discussed above are significant here because they highlight that the monoglossia may not have been "internally persuasive" for at least some of the educators. Bakhtin (1981, p.345) argues that, in contrast to authoritative discourses which draw their force from external authority such as political stature or economic power as well as social imaginaries, "internally persuasive" discourses are those which are draw on no such authority, may not even be recognised, and are interwoven with "one's own word". Internal persuasiveness is not merely about the freedom to accept an idea, but it implies ongoing engagement with heteroglossic voices where "ideas that embody diverse voices collide with each other in a dialogue that tests these ideas" (Matusov 2007, p.230),

In contrast, the authoritative monoglossia in Westside Nursery ended up obfuscating important political and ethical questions about violently-themed play, at very least in the more public realm of policy and educational meetings. Authoritative discourse, notes Bakhtin (1981), is fixed and calcified demanding total affirmation, or rejection, rather than allowing itself to be creatively reworked. For instance, the monoglossic unity in the setting, however unstable, of 'following (boy) children's interests' erased more public dialogue about the relationship between desire and the political economy or bodies and the gendered social order. The monoglossic positing of adult-child social relations in terms of protectionism and intervention instantiates one-dimensional conceptualisations of childhood itself: as a stage of life on the road to the gold-standard of adulthood. This also renders invisible children's situated knowledge and capabilities. However, some of the players in this study used the enactment of death as a way to influence play and promote intervention from others, indicating (at least some) children's interest in and ability to attend to the needs of another through caring touch as well as other more affective/emotional means (Rosen, in press). By situating adults as those who have the ability and power to forbid or recuperate such play, such monoglossia leaves untouched the possibilities that adult-child relations could be different making questions such as "How can adults and children make educational decisions together?" or "How do children negotiate dissonance, discomfort and contradiction in play?" seem almost nonsensical. Limiting pedagogical interventions to "moving them on" reproduces a neo-liberal logic of incessant change and reduces children to human capital making questions such as: "What new ways of being are possible, or made possible, in play?" seem impractical and unnecessary, despite evidence in other scholarly work that this is indeed possible within play (Marjanovic-Shane and White 2014; Edmiston 2008).

Indeed, in seeking to hold together the contradictory positions of a policy of permission but disavowal in practice, discussion about the themes, content, and subjectivities involved in violently-themed play - as well as their relationship to larger social questions such as: "What 
world do we want to live in?" - became largely implicit, even absent, despite the ever present heteroglossia. As White (2009) similarly points out in relation to assessment regimes and the possibilities of recognising toddlers' varied communication acts, centripetal forces can constrain not just what is uttered, but what is held open to consideration and dialogue. Yet, the ethnographic data generated in this study suggests that such play is about much more than violence: it is deeply entangled with questions about personhood, power relations, friendship, and the ways in which the social world is organised and understood.

\section{Concluding thoughts}

In thinking with the Bakhtinian circle, this paper has offered an in-depth exploration of early years policy as well as educator narratives of and responses to violently-themed play. It has suggested that monoglossic truth claims, which in this paper tended towards reproducing childhood to a space of instrumentality or protectionism, can come to dominate. Whilst heteroglossia did not disappear, the paper points to the way that particular ideas and practices were rendered silent when they challenged the authoritative account of violentlythemed play as 'permitted in policy, taboo in practice'. The paper has indicated the usefulness of Bakhtinian theorising as a way to investigate double-voice narratives and practices, using this to reconsider the authoritative and taken-for-granted. The importance of Bakhtin's insistence on the distal, as well as the immediate audience, in populating the utterance has been stressed. An addition to other scholarship on violently-themed play has been turning the gaze away from attempts to predict its impact on children's futures. The importance of examining the ways in which adult imaginaries of childhood are implicated in such preoccupations as well as the ways they become entangled with responses to children's violently-themed play has been stressed.

On one level the broader claim here is that centripetal forces become most apparent when their posited unity is violated. This suggests that practices which are constituted as matter out of place, such as violently-themed play, are a key location for further Bakhtinian dialogue. On another level, the argument returns to Bakhtin's hopeful assessment of the potentiality of heteroglossia and its creative, even transformative, possibilities. The focus in this paper has been on heteroglossia within responses to violently-themed play, but here the paper also points to the heteroglossic space of play itself (see also Cohen 2009). Rather than treating violently-themed play as a source or solution of society's problems, as it has been in much popular and professional literature, the suggestion here is that such play needs to be understood as a far more complex engagement with the world involving the "coauthoring [of] multiple dialogues" (Marjanovic-Shane and White 2014, p.120). As a result, the argument here is not that educators should simply allow violently-themed play in their 
settings. Nor is the suggestion that such play inherently produces ethical identities (Edmiston 2008) or challenges to the existing social order. Instead, the suggestion for early childhood educators is to consider the ways that play, as a heteroglossic space, may allow both adult and child players to explore new social imaginaries about who children and adults might be; as well as to critically engage with questions about the worlds that we do not want to live in as well as those we do.

\section{References}

Albon, D., \& Rosen, R. (2014). Negotiating adult-child relationships in early childhood research. London: Routledge.

Bakhtin, M. (1986). Speech genres and other late essays (1st ed.). Austin: University of Texas Press.

Bakhtin, M. M. (1981). The dialogic imagination: four essays. Austin: University of Texas Press.

Ball, S. J. (2003). The teacher's soul and the terrors of performativity. Journal of Education Policy, 18(2), 215-228.

Bialostok, S., \& Kamberelis, G. (2010). New capitalism, risk, and subjectification in an early childhood classroom. Contemporary Issues in Early Childhood, 11(3), 299-312.

Bradbury, A. (2011). Equity, ethnicity and the hidden dangers of 'contextual' measures of school performance. Race Ethnicity and Education, 14(3), 277-291.

Brooker, L. (2011). Taking children seriously: an alternative agenda for research? Journal of Early Childhood Research, 9(2), 137-149.

Browne, N. (2004). Gender equity in the early years. Maidenhead, Berkshire: Open University Press.

Burkitt, I. (1998). The death and rebirth of the author: the Bakhtin circle and Bourdieu on individuality, language and revolution. In M. M. Bell, \& M. Gardiner (Eds.), Bakhtin and the human sciences (pp. 163-180). London: Sage.

Christensen, P. (2000). Childhood and the cultural constitution of vulnerable bodies. In A. Prout (Ed.), The body, childhood and society (pp. 38-59). Houndmills: Macmillan Press.

Cohen, L. E. (2009). the heteroglossic world of preschoolers' pretend play. Contemporary Issues in Early Childhood, 10(4), 331-342.

Connor, K. (1989). Agression: is it in the eye of the beholder? Play and Culture, 2(3), 213217.

Dahlberg, G., \& Moss, P. (2005). Ethics and politics in early childhood education (Contesting early childhood series). London: RoutledgeFalmer.

Dahlberg, G., Moss, P., \& Pence, A. (2007). Beyond quality in early childhood education: languages of evaluation (2nd ed.). London: Routledge.

Department of Children, Schools and Families (2007). Confident, capable and creative: supporting boys' achievements: guidance for practitioners in the early years foundation stage. London: Department for Children, Schools and Families.

Department for Education (2012). Maintained nursery schools. Retrieved from http://www.education.gov.uk/schools/leadership/typesofschools/maintained/a001983 57/maintained-nursery-schools.

Douglas, M. (1966). Purity and danger: an analysis of concepts of pollution and taboo. London: Routledge \& Kegan Paul.

Dunn, J., \& Hughes, C. (2001). "I got some swords and you're dead!": violent fantasy, antisocial behavior, friendship, and moral sensibility in young children. Child Development, 72(2), 491-505. 
Dyson, A. H. (1997). Writing superheroes: contemporary childhood, popular culture, and classroom literacy. New York: Teacher's College Press.

Edmiston, B. (2008). Forming ethical identities in early childhood play. Abingdon, Oxon: Routledge.

Goldstein, J. (1995). Agressive toy play. In A. Pellegrini (Ed.), Future of play theory (pp. 127150, SUNY series). New York: State University of New York Press.

Holland, P. (2003). We don't play with guns here: war, weapon and superhero play in the early years. Maidenhead: Open University Press.

Jones, L., Holmes, R., MacRae, C., \& MacLure, M. (2010). Documenting classroom life: how can I write about what I am seeing? Qualitative Research, 10(4), 479-491.

Levin, D. E., \& Carlsson-Paige, N. (2006). The war play dilemma: what every parent and teacher needs to know (2nd ed., Early childhood education series). New York ; London: Teachers College Press.

Löfdahl, A. (2006). Grounds for values and attitudes: children's play and peer-cultures in preschool. Journal of Early Childhood Research, 4(1), 77-88.

Marjanovic-Shane, A., \& White, E. J. (2014). When the footlights are off: a Bakhtinian interrogation of play as postupok. International Journal of Play, 3(2), 119-135.

Matusov, E. (2007). Applying Bakhtin scholarship on discourse in education: a critical review essay. Educational Theory, 57(2), 215-237.

Moss, P. (2011). Analysis: progress or pitfall on child poverty strategy? Retrieved from http://www.nurseryworld.co.uk/news/1057614/Analysis-Progress-pitfall-child-povertystrategy/?DCMP=ILC-SEARCH.

Moss, P. (2012). Governed markets and democratic experimentalism: two possibilities for early childhood education and care. In A. T. Kjorholt, \& J. Qvortrup (Eds.), The modern child and the flexible labour market (pp. 128-149). London: Palgrave Macmillan.

Parsons, A., \& Howe, N. (2006). Superhero toys and boys' physically active and imaginative play. Journal of Research in Childhood Education, 20(4), 287-300.

Pellegrini, A. (2006). The development and function of rough-and-tumble play in childhood and adolescence: a selection theory perspective. In A. Goncu, \& S. Gaskins (Eds.), Play and development: evolutionary, sociocultural and functional perspectives (pp. 77-98). Mahwah, New Jersey: Lawrence Erlbaum Associates, Inc.

Penn, H. (2011). Gambling on the market: the role of for-profit provision in early childhood education and care. Journal of Early Childhood Research, 9(2), 150-161.

Rosen, R. (in press). The use of the death trope in peer culture play: grounds for rethinking children and childhood? International Journal of Play.

Singer, D. (1994). Play as healing. In J. Goldstein (Ed.), Toys, play and child development (pp. 147-165). Cambridge: Cambridge University Press.

Smith, K. (2011). Producing governable subjects: Images of childhood old and new. Childhood, 19(1), 24-37.

Spry, D. (2013). Fear and hope: the politics of childhood and mobile media. In A. N. Valdivia (Ed.), The international encyclopaedia of media studies: Volume VI: media studies futures (pp. 1-28). London: Blackwell Publishing.

Sutton-Smith, B. (1997). The ambiguity of play. Cambridge, Massachusetts: Harvard University Press.

Sylva, K., Melhuish, E., Sammons, P., Siraj-Blatchford, I., Taggart, B., \& Elliot, K. (2003). The effective provision of pre-school education (EPPE) Project: findings from the preschool period: research brief. London: Institute of Education.

Tobin, J., \& Kurban, F. (2009). 'They don't like us': reflections of Turkish children in a German preschool. Contemporary Issues in Early Childhood, 10(1), 24-34.

Valentine, G. (1996). Angels and devils: moral landscapes of childhood. Environment and Planning D: Society and Space, 14(5), 581-599.

Valle, I. L., Gibb, J., Brzyska, B., Durbin, B., Sharp, C., Aston, H., et al. (2011). Feasibility study for the trials of payment by results for children's centres. London: National Children's Bureau. 
Vološinov, V. N. (1986). Marxism and the philosophy of language. Cambridge, Mass.: Harvard University Press.

White, E. J. (2009). Assessment in New Zealand early childhood education: a bakhtinian analysis of toddler metaphoricity. PhD, Monash University, Monash.

Wyver, S., Little, H., Tranter, P., Bundy, A., Naughton, G., \& Sandseter, E. B. H. (2010). Ten ways to restrict children's freedom to play: the problem of surplus safety.

Contemporary Issues in Early Childhood, 11(3), 263-277. 